\title{
Exploitation of chromosome 4S', from Aegilops sharonensis, for the production of stable 44-chromosome wheat lines
}

\author{
I. P. KING, K. A. PURDIE, T. E. MILLER, C. N. LAW \& W. J. ROGERS \\ Cambridge Laboratory, Colney Lane, Norwich NR4 7UJ, U.K.
}

\begin{abstract}
A number of chromosomes from species related to wheat carry genes of potentially high agronomic value. However, wheat lines carrying an additional pair of such chromosomes have never been exploited commercially because they are unstable and the extra chromosomes are frequently lost during gametogenesis. In order to overcome this problem translocations involving the long arm of the Aegilops sharonensis chromosome $4 \mathrm{~S}^{\mathrm{l}}$, which carries the gene(s) determining preferential transmission, and the long and short arms of chromosome 1U from Aegilops umbellulata, which carry respectively the genes Glu-Ul and $G l i-U 1$, which affect bread making quality, have been isolated. These translocations are stable and preferentially transmitted.
\end{abstract}

Keywords: Aegilops sharonensis, preferential transmission, protein quality, stable additions, Triticum aestivum.

\section{Introduction}

A number of chromosomes from species related to bread wheat (Triticum aestivum) have been shown to carry genes of potentially high agronomic value when introduced into wheat (e.g. Knott, 1968; Forster et al., 1988), but lines carrying an additional pair of such 'alien' chromosomes have never been exploited commercially. One reason for this is that the alien homologues in wheat alien addition lines sometimes fail to pair at meiosis (Riley, 1960), resulting in reversion to pure wheat. The phenomenon of preferential transmission exhibited by chromosome $4 \mathrm{~S}^{\mathrm{l}}$ of Aegilops sharonensis, when present in a wheat background, ensures that all gametes lacking it are non-functional (Miller et al., 1982). Thus one way in which the cytological instability of disomic addition lines could be overcome would be to induce a translocation between an alien chromosome and the segment of the long arm of chromosome $4 \mathrm{~S}^{\mathrm{l}}$, which carries the gene(s) for preferential transmission (King et al., 1991b). Lines disomic for such a novel chromosome (42 wheat chromosomes + two $4 \mathrm{~S}^{\prime} \mathrm{L} /$ alien translocation chromosomes) would be expected to be stable 44-chromosome lines, as normal 21-chromosome wheat gametes (lacking the translocation) will be inviable due to the gametocidal action of the gene(s) for preferential transmission on $4 \mathrm{~S}^{\mathrm{l}}$. The simple way to induce the required translocations is via centric breakage and fusion (Robertsonian translocations) which have been shown to occur between unrelated chromosomes (Driscoll \& Sears, 1963; Davies et al., 1985).

The current paper reports the production of three translocations between chromosome $4 \mathrm{~S}^{\mathrm{l}}$ and chromosome $1 \mathrm{U}$ from Aegilops umbellulata. The latter chromosome carries genes encoding endosperm storage proteins of potential value in manipulating breadmaking quality: Glu-Ul on the long arm, encoding high-molecular-weight (HMW) subunits of glutenin, and $G l i-U 1$ on the short arm, encoding gliadins.

\section{Materials and methods}

The genetic material consisted of the $T$. aestivum variety Chinese Spring (CS), and the Chinese Spring $4 S^{\mathrm{l}}$ and $1 \mathrm{U}$ disomic addition lines. As the first step in the induction of $4 S^{\prime} L / 1 U$ translocations, the $1 \mathrm{U}$ and $4 S^{\mathrm{j}}$ additions were intercrossed, and progeny with 44 chromosomes were selected. When plants containing chromosome $4 S^{l}$ are used as the pollen parent in crosses to plants without $4 \mathrm{~S}^{\mathrm{l}}$, chromosomal aberrations are frequently observed in the progeny (Endo, 1988). To avoid this problem, the CS $1 \mathrm{U}$ disomic addition line was used as the pollen parent and the CS $4 S^{1}$ disomic addition line as the female parent. The resultant double monosomic addition lines $\left(42 W+4 S^{1}+1 U\right)$ 
were expected to form 21 bivalents and a $4 S^{l}$ and a $1 \mathrm{U}$ univalent at meiosis. As univalents occasionally misdivide and rejoin, some gametes would be expected to contain a $4 \mathrm{~S}^{\mathrm{l}} \mathrm{L} / 1 \mathrm{U}$ translocation chromosome. The double monosomic addition lines were subsequently used as the pollen parent in crosses with CS euploid. Although carrying out the cross in this direction would be expected to result in some of the progeny containing chromosomal aberrations, this was necessary because the presence of a monosomic chromosome $4 \mathrm{~S}^{\mathrm{l}}$ can result in a reduction in female fertility of up to 75 per cent (King, 1990). Although male fertility is also reduced, the problem is not severe due to the large pollen population. Identification of $4 S^{\prime} \mathrm{L} / 1 \mathrm{U}$ Robertsonian translocations in the $42 \mathrm{~W}+4 \mathrm{~S}^{1}+1 \mathrm{U}$ $\times C S \quad F_{1}$ individuals was facilitated by screening for the presence or absence of the following genetic markers: Amp-S 2 on $4 \mathrm{~S}^{\mathrm{l}} \mathrm{S}$, encoding an aminopeptidase isozyme (King et al., 1991c); $\beta-A m y-S^{l} 1$ on $4 \mathrm{~S}^{\mathrm{l}} \mathrm{L}$, encoding certain $\beta$-amylase isozymes (King et al., 1991c); Gli-U1 on 1US, encoding gliadins (Brown et al., 1979); Glu-U1 on 1UL, encoding two HMW subunits of glutenin (Brown et al., 1979). All these nonwheat isozymes/proteins are electrophoretically distinct from their wheat equivalents. Since, as noted earlier, the gene(s) for preferential transmission is on $4 S^{l} \mathrm{~L}, 42 \mathrm{~W}+4 S^{\mathrm{l}}+1 \mathrm{U} \times \mathrm{CS}$ individuals carrying the desired translocation would be expected to possess $\beta-A m y-S^{\prime} 1$ on $4 S^{l} \mathrm{~L}$ and lack $A m p-S^{\prime} 2$ on $4 S^{\mathrm{l}} S$; they would also carry one or other of Glu-U1 on $1 \mathrm{UL}$ or Gli-U1 on 1US. Thus initial selection was carried out by screening for the absence of $A m p-S^{\prime} 2$. Individuals which lacked this marker were then screened for the remaining three markers.

Isoelectric focusing separations of the isozymes were carried out according to Sharp et al. (1988) for $\beta$ amylase and Koebner \& Martin (1989) for aminopeptidase. Glutenins and gliadins were fractionated using 10 per cent SDS-PAGE under reducing conditions as described by Payne et al. (1981), except that 2-mercaptoethanol was replaced by dithiothreitol ( 50 $\mathrm{mM})$ as the reducing agent in the sample buffer.

Somatic chromosome counts were obtained from root-tip preparations and meiotic configurations from pollen mother cells, both stained by the standard Feulgen procedure.

\section{Results}

Two thousand and thirty-nine individual grains were produced from the $42 \mathrm{~W}+4 \mathrm{~S}^{l}+1 \mathrm{U} \times \mathrm{CS}$ cross; of these, 1839 individuals possessed $A m p-S^{\prime} 2$ and were therefore discarded. Eighty-nine of the remaining 200 individuals lacked $\beta-A m y-S^{\prime} 1$ as well as $A m p-S^{\prime} 2$, and presumably lacked chromosome $4 \mathrm{~S}^{1}$, these individuals were not studied further. Ninety-six of the $A m p-S^{\prime} 2^{-}$, $\beta-A m y-S^{\prime} 1^{+}$selections carried neither Glu-U1 nor Gli$U 1$ and hence, presumably, lacked chromosome $1 \mathrm{U}$ entirely. Mitotic observations of the 96 seedlings revealed the presence of 42 bibrachial chromosomes and a single telosome, probably $4 \mathrm{~S}^{\mathrm{l}} \mathrm{L}$. Of the remaining 15 selections 12 had both Glu-U1 and Gli-U1 and carried 43 bibrachial chromosomes and one telosome, indicating the likely presence of a complete $1 \mathrm{U}$ chromosome and a $4 \mathrm{~S}^{\mathrm{l}}$ telosome. Two of the remaining three individuals ( 306 and 348), possessed Glu-U1 but not Gli-U1, while the other (304) had Gli-U1 but not Glu-U1. All three plants contained 43 bibrachial chromosomes and formed 21 bivalents and a univalent at metaphase I of meiosis. The univalent chromosomes possessed a single distinctive telomere (Fig. 1a and b). In contrast, $4 S^{\mathrm{l}}$ univalent chromosomes possess two distinctive telomeres (King et al., 1991a). Thus the presence of only one distinctive telomere on the univalent chromosome, in each of the three plants, is consistent with the presence of a translocation involving $4 \mathrm{~S}^{1}$. The biochemical phenotypes, the absence of telosomes, plus the meiotic configuration, indicated that plants 306 and 348 contained a $4 S^{\prime} L / 1 U L$ translocation, while plant 304 contained a $4 S^{l} L / 1 U S$ translocation. The short arm of chromosome $1 \mathrm{U}$ possesses a nucleolus organizer region (NOR) which suppresses the activity of the four wheat NORs (Martini et al., 1982). Thus in Chinese Spring $1 U$ addition lines, only the 1U NORs are visible. Mitotic preparations of plant 304 revealed that only one NOR chromosome was usually observed. At metaphase I of meiosis the NOR was located on the univalent chromosome, confirming the presence of a $4 S^{1} \mathrm{~L} / 1 \mathrm{US}$ translocation in this plant (Fig. 1b). Four NOR chromosomes were regularly seen in mitotic and meiotic preparations of plants 306 and 348. At metaphase I of meiosis, the univalent in these plants did not appear to have a NOR (Fig. 1a).

In order to determine whether the translocations were preferentially transmitted, plants 306,348 and 304 were test-crossed as pollen parents to Chinese Spring and the progeny screened with the biochemical markers. The majority of individuals in the three testcross populations had both $\beta-A m y-S^{\prime} 1$ and Glu-U1 (84.6 per cent of the $306 \times$ CS test-cross progeny and 87.5 per cent of the $348 \times$ CS test-cross progeny), or Gli-U1 (93.8 per cent of the $304 \times$ CS test-cross progeny), consistent with the preferential transmission of the $4 S^{l} \mathrm{~L} / 1 \mathrm{U}$ chromosome (Table 1 ). Note that plant 348 was relatively male sterile and only eight $348 \times$ CS progeny were obtained.

Six test-cross progeny (three from $304 \times$ CS and three from $306 \times \mathrm{CS}$ ) lacked the relevant storage pro- 


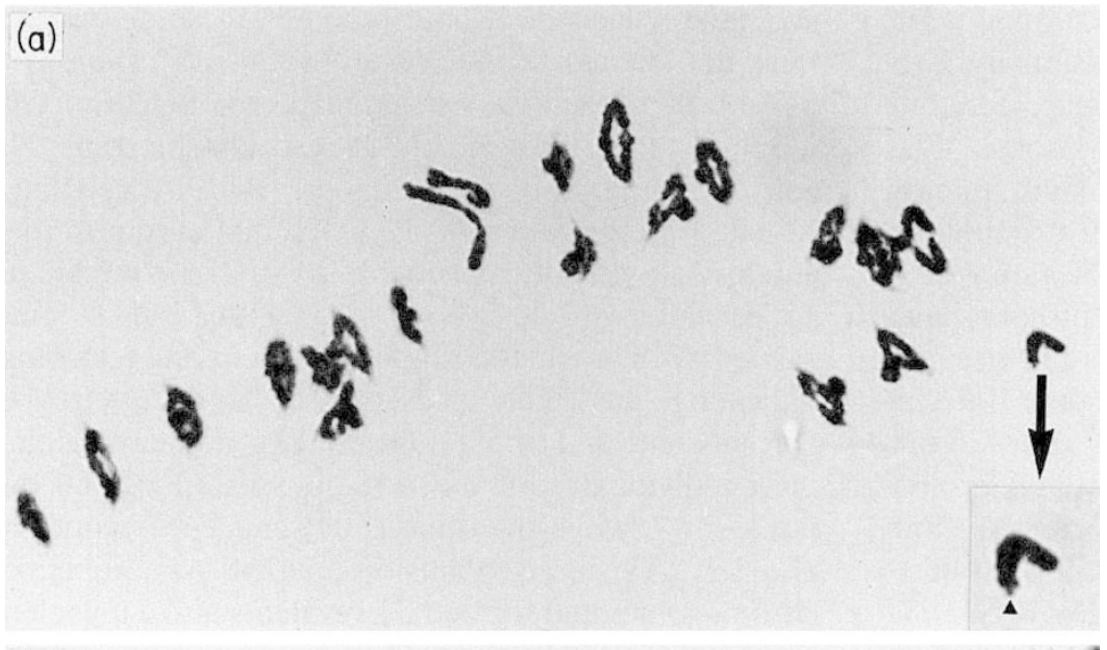

(b)

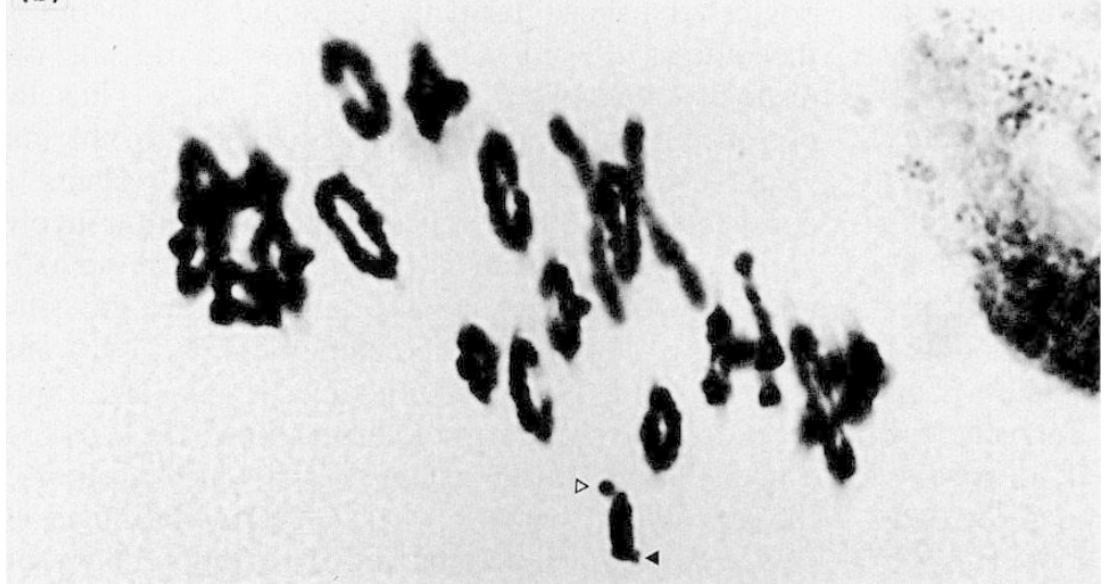

Fig. 1 Two photomicrographs; one from plant 306 (a) and the other from plant 304 (b). Each shows 21 bivalents and a univalent chromosome [the univalent in $(b)$ is enlarged in an insert]. Each univalent has a distinctive telomere $(\boldsymbol{\Delta})$. The univalent from plant 304 also possesses a $\operatorname{NOR}(\Delta)$.

Table 1 The number of individuals from the three test-cross progenies with or without $\beta$-Amy-S $1, G l u-U l$ and $G l i-U 1$

\begin{tabular}{|c|c|c|c|c|}
\hline & $\beta-A m y-S^{\prime} 1^{+}$ & $\beta-A m y-S^{l} 1^{+}$ & $\beta$-Amy-S $1^{+}$ & $\beta-A m y-S^{\prime} l^{-}$ \\
\hline Test cross & Glu-U1- Gli-U1+ & Glu-UI $1^{+}$Gli-U1 $1^{-}$ & Glu-U1- Gli-U1- & Gli-U1- Gli-Ul' \\
\hline $304 \times \mathrm{CS}$ & 45 & - & 3 & - \\
\hline $306 \times \mathrm{CS}$ & - & 22 & 3 & 1 \\
\hline $348 \times \mathrm{CS}$ & - & 7 & - & 1 \\
\hline
\end{tabular}

tein ( $G l i-U 1$ and $G l u-U 1$, respectively) but had $\beta$-Amy$S^{\prime} 1$. Of these one plant from each test-cross progeny possessed a dicentric chromosome. The biochemical phenotype of these individuals could be explained by a translocation which involved the $4 \mathrm{~S}^{\mathrm{1}} / 1 \mathrm{U}$ translocation chromosome and a wheat chromosome, such that $\beta$ $A m y-S^{\prime} 1$ was included in the dicentric chromosome, while the $1 \mathrm{U}$ segment was lost as an acentric fragment. Two plants from each test-cross progeny possessed 42 bibrachial chromosomes and one telosome. The loss of either $G l u-U 1$ or $G l i-U 1$ in these plants was probably the result of misdivision of $4 \mathrm{~S}^{\mathrm{l}} \mathrm{L} / 1 \mathrm{U}$ followed by loss of the $1 \mathrm{U}$ telosome. A further two plants, one from testcross progeny $306 \times \mathrm{CS}$ and the other from test-cross progeny $348 \times \mathrm{CS}$, lacked both $\beta-A m y-S^{l} 1$ and Glu-U1 and had 42 bibrachial chromosomes. It appears that the $4 S^{l} \mathrm{~L} / 1 \mathrm{UL}$ translocation chromosomes were not transmitted to these two individuals. A number of individuals from each test-cross progeny, which possessed the relevant $4 S^{1}$ and $1 U$ markers, contained 
Table 2 Chromosome number of plants produced upon self-pollination of plants monosomic for the three $4 S^{\prime} \mathrm{L} / 1 \mathrm{U}$ translocations

\begin{tabular}{llc}
\hline & \multicolumn{2}{l}{$\begin{array}{l}\text { Chromosome number of } \\
\text { selfed progeny }\end{array}$} \\
\cline { 2 - 3 } Parents & 44 & 45 \\
\hline 304 & 17 & - \\
306 & 21 & 2 \\
348 & 22 & - \\
Totals & 60 & 2 \\
\hline
\end{tabular}

chromosomal aberrations, deletions and dicentric chromosomes.

To reaffirm that the three translocations were preferentially transmitted, 43-chromosome monosomic addition individuals $\left(42 \mathrm{~W}+4 \mathrm{~S}^{\mathrm{l}} / 1 \mathrm{U}\right)$ from each of the three progenies were selected and those forming 21 bivalents and a single univalent at metaphase I of meiosis were allowed to self-fertilize. With only two exceptions, the progeny produced from these plants contained 44 bibrachial chromosomes, demonstrating that the translocations are preferentially transmitted (Table 2). The two exceptions, derived from the selffertilization of plants monosomic for the 306 translocation, contained 45 chromosomes, indicating trisomy for an, as yet unidentified, chromosome. In contrast to the three test-cross progenies $\mathrm{CS} \times 306$, $\mathrm{CS} \times 348$, and $\mathrm{CS} \times 304$, none of the progeny derived from self-fertilization of the $42 \mathrm{~W}+4 \mathrm{~S}^{\mathrm{l}} \mathrm{L} / 1 \mathrm{U}$ individuals contained chromosome aberrations.

\section{Discussion}

The transmission frequency of alien monosomes added to the euploid wheat complement is normally low. When these plants are allowed to self pollinate, about 75 per cent of the progeny are euploid $(2 n=42$, no alien chromosome), about 25 per cent are monosomic additions $(2 n=43$, including one alien chromosome), and only a small proportion are disomic additions $(2 n=44$, including a pair of alien chromosomes) (Evans \& Jenkins, 1960; Islam et al., 1981; Miller, 1982). However, for the three translocated chromosomes produced in the current study, all but two of the 62 progeny derived from self-fertilization of the $42 \mathrm{~W}+4 \mathrm{~S}^{\mathrm{l}} \mathrm{L} / 1 \mathrm{U}$ individuals possessed 44 chromosomes and none contained less than 44 chromosomes. Furthermore, the majority of progeny produced from each of the three crosses with the euploid CS possessed $\beta-A m y-S^{\prime} 1$ and the relevant $1 \mathrm{U}$ marker. It is therefore concluded that the three $4 S^{l} \mathrm{~L} / 1 \mathrm{U}$ translocations are preferentially transmitted.

If the translocations are to be exploited they must be stable, i.e. they must not revert at high frequency into their component telosomes. Misdivision of the translocation was detected only four times in the three test-cross progenies, and never in individuals derived from self-fertilization of the monosomic additions $\left(42 \mathrm{~W}+4 \mathrm{~S}^{\mathrm{l}} \mathrm{L} / 1 \mathrm{U}\right)$. These data demonstrate that the three translocations are sufficiently stable for use in plant breeding programmes.

If the unrelated alien monosomes in a double monosomic addition act independently their frequencies of fission and transmission should be predictable from those observed in the two relevant single monosomic additions. The frequencies of occurrence in the progeny of the newly formed telosomes $4 \mathrm{~S}^{\mathrm{l}} \mathrm{L}$, 1UL and 1US, from their respective complete monosomes, have been observed to be 0.89 (King et al., 1991b), 6.0 and 5.1 per cent (Koebner \& Shepherd, 1987), and one therefore would expect to obtain individuals simultaneously carrying the two telosomes $4 \mathrm{~S}^{\mathrm{l}} \mathrm{L}$ and $1 \mathrm{UL}$, or $4 \mathrm{~S}^{\mathrm{L}} \mathrm{L}$ and $1 \mathrm{US}$ at frequencies of 0.05 and 0.04 per cent, respectively, equivalent to $1.0\left(4 \mathrm{~S}^{\mathrm{l}} \mathrm{L}\right.$ and $\left.1 \mathrm{UL}\right)$ and 0.8 $\left(4 S^{1} \mathrm{~L}\right.$ and $\left.1 \mathrm{US}\right)$ in a population of 2039. Although individuals carrying a $4 \mathrm{~S}^{\mathrm{L}} \mathrm{L}$ and a $1 \mathrm{U}$ telosome were not observed, three $4 S^{1} \mathrm{~L} / 1 \mathrm{U}$ translocations were isolated which seems to indicate that the products of misdivision of chromosomes $4 \mathrm{~S}^{\prime} \mathrm{L}$ and $1 \mathrm{U}$ are very likely to fuse if they occur in the same cell as suggested by Sears (1972).

Several individuals from each test-cross progeny contained chromosomal aberrations such as deletions and dicentric chromosomes. In contrast the progeny derived from self-fertilization of plants monosomic for the translocations did not. The significant difference here could be that in the former case only the pollen contained $4 \mathrm{~S}^{\mathrm{l}} \mathrm{L}$, and hence chromosome aberrations were expected (Endo, 1988), while in the latter case both male and female viable gametes should have contained $4 \mathrm{~S}^{l} \mathrm{~L}$.

The three translocations described in this work demonstrate the potential of utilizing the long arm of chromosome $4 \mathrm{~S}^{\mathrm{l}}$ for the production of stable addition lines. However, the successful application of these translocations to breeding programmes will depend on their effect on agronomic characters. Lines which carry the translocations may be inferior to euploid wheat due to either the presence of deleterious genes on the alien chromatin (Knott, 1968; 1980), or increased gene dosage. In the first case, attempts could be made to mutate the deleterious genes, while in the second case, selection for null alleles might alleviate the problem. In some circumstances, the agronomic advantages con- 
ferred by the additional chromosomes may be so significant that some reduction in yield is acceptable. For example, chromosome $5 \mathrm{E}^{\mathrm{b}}$ from Thinopyrum bessarabicum confers tolerance to relatively high salt concentrations (Forster et al., 1988). If a $4 \mathrm{~S}^{\mathrm{l}} \mathrm{L} / 5 \mathrm{E}^{\mathrm{b}}$ translocation can be induced, 44-chromosome plants carrying it may be able to grow in areas where the salt concentration is too high for normal 42-chromosome wheat varieties. In this situation a reduction in yield observed under normal salt concentration, as a result of the alien translocation chromosome, would be acceptable.

Returning to the current study, the translocations involving $1 \mathrm{UL}$ carry Glu- $U 1$ encoding two HMW subunits of glutenin, which, by the construction of the stably inherited addition chromosomes described here, have been added to the wheat genome. There is some evidence that adding extra doses of particular HMW subunits, or increasing the number of different subunits carried by a wheat, leads to increases in gluten strength (Rogers, et al., 1990; 1991), which is an important factor in bread-making. There is also evidence that the particular subunits encoded by $G l u-U 1$ in the accession of Ae. umbellulata, used here, increase gluten strength in wheat when a chromosome segment carrying Glu-Ul is substituted for the segment carrying the Glu-Al locus on chromosome $1 \mathrm{~A}$. Thus, there is good reason to believe that the lines produced here would show increases in gluten strength. The effect of the other translocation line, carrying Gli-Ul added to the wheat genome, appears less predictable; in a CS background, gluten strength is enhanced when a chromosome segment carrying this locus replaces the segment carrying $G l i-A 1$ on $1 \mathrm{~A}$, but is reduced when it replaces the corresponding segments carrying Gli-Bl on $1 \mathrm{~B}$ or Gli-D1 on 1D (Islam-Faridi, 1988; Harris, 1983; Rogers et al., 1987). Additionally, there are possible yield advantages associated with segments carrying Gli-Ul (Islam-Faridi, 1988, Harris, 1983). Further work is therefore required to assess the agronomic potential of lines carrying the three $4 S^{l} \mathrm{~L} / 1 \mathrm{U}$ translocations.

\section{Acknowledgements}

The authors would like to acknowledge Dr R. M. D. Koebner for his critical reading of this manuscript and Elizabeth Sayers for technical assistance.

\section{References}

BROWN, J. W. S., KEMBLE, R. J., LAW, C. N. AND FLAVELL, R. B. 1979. Control of endosperm proteins in Triticum aestivum (var. Chinese Spring) and Aegilops umbellulata by homoeo- logous group 1 chromosomes. Genetics, 93, 189-200.

DAVIES, P. A., PALlOTTA, M. A. AND DRISCOLL, C. J. 1985. Centric fusion between nonhomologous rye chromosomes in wheat. Can. J. Genet. Cytol., 27, 287-632.

DRISCOLL, C. J. AD SEARS, E. R. 1963. The nature of a spontaneous transfer of hairy neck from rye to wheat. Proc. XI Congr. Genet., 1, 123.

ENDO, T. R. 1988. Chromosome mutations induced by gametocidal chromosomes in common wheat. In: Miller, T. E. and Koebner, R. M. D. (eds), Proceedings of the 7th International Wheat Genetics Symposium. Institute of Plant Science Research, Cambridge U.K., pp. 259-265.

EVANS, L. E. AND JENKINS, B. c. 1960. Individual Secale cereale chromosome additions to Triticum aestivum. The addition of individual 'Dakold' rye chromosomes to 'Kharkov' winter wheat and their subsequent identification. Can. J. Genet. Cytol., 2, 205-215.

FORSTER, B. P., MILLER, T. E. AND LAW, C. N. 1988. Salt tolerance of two wheat-Agropyron junceum addition lines. Genome, 30, 559-564.

HARRIS, P. A. 1983. The genetics and biochemistry of grain proteins in wheat. $\mathrm{PhD}$ Thesis, University of Cambridge, U.K.

ISLAM-FARID1, M. N. 1988. Genetical studies of grain protein and developmental characters in wheat. $\mathrm{PhD}$ Thesis, University of Cambridge, U.K.

ISLAM, A. K. M. R., SHEPHERD, K. W. AND SPARROW, D. H. B. 1981. Isolation and characterization of euplasmic wheat-barley addition lines. Heredity, 46, 161-174.

K1NG, 1. P. 1990. Cytogenetical studies on a preferentially transmitted chromosome from Aegilops sharonensis. $\mathrm{PhD}$ thesis, Institute of Plant Science Research, Cambridge.

KING, 1. P., KOBNER, R. M. D., READER, S. M. AND MILLER, T. E. 1991a. Induction in the male fertility gene of the preferentially transmitted Aegilops sharonensis chromosome $4 \mathrm{~S}^{1}$ and its application for hybrid wheat production. Euphytica, 54, 33-39.

KING, 1. P., KOEBNER, R. M. D., SCHLEGEL, R., READER, S. M., MILLER, T. E. AND LAW, C. N. 1991b. Exploitation of a preferentially transmitted chromosome from Aegilops sharonensis for the elimination of segregation for height in semi-dwarf bread wheat varieties. Genome, 34, 944-949.

KING, 1. P., MILLER, T. E. AND KOEBNER, R. M. D. 1991c. Determination of the transmission frequency of chromosome $4 S^{1}$ of Aegilops sharonensis in a range of wheat genetic backgrounds. Theor. Appl. Genet., 81, 519-523.

KNOTT, D. R. 1968. Agropyrons as a source of rust resistance in wheat breeding. In: Finlay, K. W. and Shepherd, K. W. (eds),. Proceedings of the 3rd International Wheat Genetics Symposium, Canberra, Australia. pp. 204-212.

KNOTT, D. R. 1980. Mutation of a gene for yellow pigment linked to Lr19 in wheat. Can. J. Genet., 22, 651-654.

KOEBNER, R. M. D. AND MARTIN, P. K. 1989. Chromosomal control of the aminopeptidases of wheat and its close relatives. Theor. Appl. Genet., 78, 657-664.

KOEBNER, R. M. D. AND SHEPHERD, K. w. 1987. Allosyndetic recombination between a chromosome of Aegilops umbellulata and wheat chromosomes. Heredity, 59, 33-45. 
MARTINI, G., O'DELL, M. AND FLAVELL, R. B. 1982. Partial inactivation of wheat nucleulos organizer chromosomes from Aegilops umbellulata. Chromosoma, 84, 687-700.

MiLLER, T. E. 1982. Preferential transmission of alien chromosomes in wheat. In: Brandham, P. E. O. and Bennet M. D. (eds) 2nd Kew Chromosome Conference. George Allen and Unwin, London. pp. 173-182.

MiLleR, T. E., HUTCHINSON, J. AND CHAPMAN, v. 1982. Investigation of a preferentially transmitted Aegilops sharonensis chromosome in wheat. Theor. Appl. Genet., 61, 27-33.

PAYNE, P. I., HOLT, L. M. AND BLACKMAN, J. A. 1981. Correlations between the inheritance of certain high-molecular-weight subunits of glutenin and bread-making quality in progenies of six crosses of bread wheat. J. Sci. Food Agric., 32, 51-60.

RILEY, R. 1960. The meiotic behaviour, fertility and stability of wheat-rye chromosome addition lines. Heredity, 14, 89-100.

ROGERS, W. J., RICKATSON, J. M., SAYERS, E. J. AND LAW, C. N. 1990.
Dosage effects of chromosomes of homoeologous groups 1 and 6 upon bread-making quality in hexaploid wheat. Theor. Appl. Genet., 80, 281-287.

ROGERS, W. J., PAYNE, P. I. SEEKINGS, J. A. AND SAYERS, E. J. 1991. Effect on bread making quality of $x$-type and $y$-type high molecular weight subunits of glutenins. J. Cereal Sci. 14, 209-221.

ROGERS, W. J., SAYERS, E. J., HARRIS, P. A. LAW, C. N. AND PAYNE, P. I. 1987. Effect of allelic variation for glutenin subunits and gliadins on bread-making quality; exploitation of novel alleles found in wild relatives of wheat. In: Lasztity, $R$. and Bekes, F. (eds), Proceedings of the 3rd International Workshop on Gluten Proteins. World Scientific, Singapore, pp. 46-56.

SHARP, P. J., DESAI, S. AND GALE, M. D. 1988. Isozyme variation and RFLPs at the $\beta$-amylase loci in wheat. Theor. Appl. Genet., 76, 691-699.

SEARS, E. R. 1972. Chromosome engineering in wheat. Stadl. Symp., 4, 23-38. 